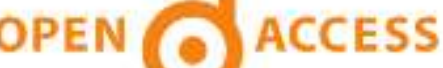 \\ International Journal of Applied Sciences and Biotechnology
}

\author{
A Rapid Publishing Journal
}

ISSN 2091-2609

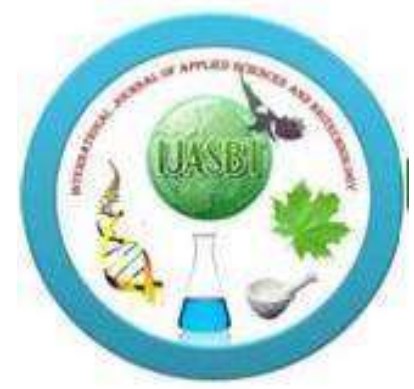

\section{Available online at:}

http://www.ijasbt.org

$\&$

http://www.nepjol.info/index.php/IJASBT/index

\section{Indexing and Abstracting}

CrossRef, Google Scholar, Global Impact Factor, Genamics, Index Copernicus, Directory of Open Access Journals, WorldCat, Electronic Journals Library (EZB), Universitätsbibliothek Leipzig, Hamburg University, UTS (University of Technology, Sydney): Library, International Society of Universal Research in Sciences (EyeSource), Journal Seeker, WZB, Socolar, BioRes, Indian Science, Jadoun Science, Jour-Informatics, Journal Directory, JournalTOCs, Academic Journals Database, Journal Quality Evaluation Report, PDOAJ, Science Central, Journal Impact Factor, NewJour, Open Science Directory, Directory of Research Journals Indexing, Open Access Library, International Impact Factor Services, SciSeek, Cabell's Directories, Scientific Indexing Services, CiteFactor, UniSA Library, InfoBase Index, Infomine, Getinfo, Open Academic Journals Index, HINARI, etc.

\section{CODEN (Chemical Abstract Services, USA): IJASKD}

Vol-2(3) September, 2014

Impact factor*: $\mathbf{1 . 4 2 2}$

Scientific Journal Impact factor\#: 3.419

SEM-Biotech

IC Value: $\mathbf{4 . 3 7}$

Publishing

*Impact factor is issued by Universal Impact Factor. Kindly note that this is not the IF of Journal Citation Report (JCR).

"Impact factor is issued by SJIF INNO SPACE. 


\title{
Research Article \\ STUDIES IN GROWTH PARAMETER AND PIGMENT CONTENTS IN ENDOSULPHAN, EC- 35 EXPOSED BLUE GREEN ALGA (Anabena cylindrica, L.)
}

\author{
Goutam Sabat $^{1 *}$, A.K. Panigrahi ${ }^{2}$, A.K. Sahu ${ }^{3}$ and B.K. Mohanty ${ }^{1}$ \\ ${ }^{1}$ P.G Department of Botany and Biotechnology, Khallikote Autonomous College, Berhampur-760 001, Odisha, India \\ ${ }^{2}$ P.G.Department of Botany, Berhampur University, Berhampur-760007, Odisha, India \\ ${ }^{3}$ Department of Botany R.N.College, Dura, Ganjam, Odisha \\ *Corresponding author's email: gsabat2010@gmail.com
}

\begin{abstract}
Anabaena cylindrica L, a blue green alga commonly found in rice fields was experimentally exposed with a board spectrum insecticide,Endosulphan,EC50 in laboratory conditions for varied days. The growth of alga in terms of increase in Absorbance, dry weight and pigments like Total chlorophyll, carotenoid and phaeophytin were estimated to study the toxic effect and the subsequent recovery from insecticide stress. The results obtained indicated decrease in all studied parameters with increase in exposure period and concentration. The highest concentration $(3.25 \mathrm{ml} / \mathrm{L})$ and highest period (15Days) severely affected the growth of alga and decreased pigment content. However, when the algae were allowed to grow in insecticide free environment for 15 days, they could able to recover fully from the toxic stress.
\end{abstract}

Keywords: Endosulphan; alga; pigment; growth; stress

\section{Introduction}

When pesticides are introduced into the environment many physio-chemical and biological forces begin to interact with them. Since these chemicals are designed as biological agents and particularly true in one group of pesticides which are designed to kill insects. As pesticides have high biological affinity, they play a vital role in understanding the behavior of pesticides. Assuming that pesticides are applied to soil or aquatic systems, one can immediately foresee two independent effects: 1. Adsorption-binding to soil or aquatic sediment particles and 2. Interaction with biological material. It has been reported that pesticides bound to soil and sediment can eventually be transferred to biological systems, though the speed of transfer will be much slower than direct reaction to biological systems (Edwards, 1973). The extensive occurrence of pests, weeds and other pathogenic diseases in the crop fields require their control in order to increase the production and a good number of toxic chemicals were extensively used to control them. Such killer chemicals were collectively called in general as pesticides. These pesticides were designed for a specific group of target system such as algicides, fungicides, nematocides, bactericides, insecticides, herbicides etc. These are generally spread in the crop fields which directly enter into the soil after spraying or by washing or by rain-wash.
The blue green alga dies or affected because of the pesticides applied in recommended doses and higher doses due to carelessness of the illiterate user. Anabaena cylindrica, Lemm., a blue-green algae is found abundantly in the crop fields contaminated with the pesticides . It is a prokaryote, good fixer of atmospheric nitrogen, and prefers slightly alkaline $\mathrm{pH}$ and water logged conditions, for its growth and multiplication (Fogg et al., 1973). It has been successfully used as a biofertilizer in paddy cultivation (Venkataraman, 1972; Kulasooriya et al., 1980). The possible role of BGA in the productivity of rice has been demonstrated by the extensive work of Singh (1961). Rodgers et al., (1979) reported that the biofertilizers can be a good substitute for synthetic nitrogen fertilizers in terms of net productivity and Venkataraman (1972) reported that biofertilizers can maintain the fertility level of the crop fields.

Anderson (1978) reported that the wide use of certain pesticides has more serious and permanent drastic effect on microorganisms. It is well established fact that nitrogenfixing organisms, particularly blue-green algae, are known to play a key role in increasing soil fertility, especially in paddy fields under water logged condition (De, 1939; Singh, 1961; Stewart, 1977). Thus, the pesticides which enter into the paddy field might be affecting the growth and nitrogen fixing capacity of the blue-green algal systems. The universal use of pesticides in agriculture creates a necessity to study the effects of these chemicals on soil 
micro-organisms (Gillberg, 1971). There are very few reports on the tolerance of blue-green algae towards aldrin, dieldrin, endrin and other metabolites (Venkataraman and Rajyalakshmi, 1972). The toxicity of the pesticides to certain nitrogen fixing soil algae was that the algae were relatively more tolerant to $100-500 \mathrm{ppm}$ of $2,4-\mathrm{D}$, the concentrations much higher than used in fields, as recommended for elimination of specific weeds (Arvick et al., 1971 and Venkataraman and Rajyalakshmi, 1972).

Keeping in view of the entry of pesticides into the crop fields, through mass spray or fumigation/periodic spray/varieties of spray and their possible effect on the nitrogen fixing blue-green algae in the crop fields; this project was designed to evaluate the eco-toxicological effects on growth, photosynthetic activity of the pesticide, Endosulfan on the blue-green alga, Anabaena cylindrica, Lemm.

\section{Materials and Methods}

Anabaena cylindrica, Lemm is photo-autotrophic, unbranched, filamentous, heterocystous, blue-green alga belonging to the family Nostocaceae was selected as test organism for the study ENDOCEL 35 E.C. is dark brown liquid consisting of Endosulfan technical 35 w.w solvent, emulsifier was the insecticide used for the experimentation in laboratory conditions.

Three concentration of Endosulphan was selected were 2.5, 3.0 and $3.25 \mathrm{ml} / \mathrm{L}$ and days of exposure were $0.3,6,9,12$ and 15 days. After the exposure the alga were allowed to recover in insecticide free condition upto 15 days again.

A suspension of the exponentially growing alga of the same age, having some biomass and same physiological conditions, was inoculated initially into the experimental flasks. Growth was estimated by withdrawing the cultures under aseptic conditions. On every third day interval, growth was measured in terms of optical density and dry weight. The optical density of the samples was measured in a spectrophotometer (Systronics -119) at $530 \mathrm{~nm}$. Dry weight of the sample was determined by drying the material in an infra-red moisture meter and weighing in a single pan electric balance. The pigment contents (Total chlorophyll, caretoniods and phaeophytin) were estimated (Arnon, 1949).

\section{Results}

In the present investigation, Table 1, where no dichotomy, in growth behavior was marked, induced by the pesticide. At all the three selected concentrations of the insecticide. Endosulfan, decline in growth rate was marked. At concentration A $(2.5 \mathrm{ml} / \mathrm{L})$, the decline in growth rate of the alga was not significant. However, with the increase in exposure period, the exposed alga showed a positive correlation $(\mathrm{r}=0.968, \mathrm{P}<0.01)$ with the increase in exposure period, when compared to the control value, a similar positive and significant trend and correlation was marked $(r=0.988, \mathrm{P}<0.01)$. At higher concentration of Endosulfan $(3.25 \mathrm{ml} / \mathrm{L})$ significant and negative correlation was marked. This indicated that the concentration of the toxicant plays a critical role in pesticide toxicity.

In case of pigment study (Table 1), the major pigments of seedling like Total chlorophyll, Phaeophytin and carotenoid were studied. There was a drastic decline in all pigments with the highest concentration $(3.25 \mathrm{ml} / \mathrm{L})$ of Endosulphan where as low concentration of pesticide has little effect. In case of Dry Wt. the effect was greater indicating low biomass production.

\section{Discussions}

Endosulfan, the pesticide showed significant difference in action at different concentrations on a blue-green alga, is well evident from the tables and figures described in the result chapter. At higher concentration of the pesticide and higher exposure period, drastic effects on the blue-green alga were observed. At the highest concentration (Conc. C) of the pesticide, the alga showed typical toxic symptoms, beyond which survival of the alga becomes extremely difficult and at times impossible under laboratory control conditions. The analysis of variance ratio tests and correlation coefficient analysis carried out for all parameters studies, indicate clearly that the pesticides, Endosulfan is extremely toxic to blue-green alga. All most all the parameters studied showed a declining trend only, in exposed cultures, when compared to control cultures. The decline in parameters can be correlated with the pesticide toxicity only, as the only difference between the control culture and exposed culture was the addition of the pesticide in exposed cultures. Hence, it can be safely concluded that the damage caused in exposed system was only due to the toxicant. This piece of work was designed to study the effects of the pesticide, Endosulfan, on growth, photosynthetic efficiency and nitrogen fixing ability of the blue-green alga, Anabaena cylindrical, Lemm.

Optical density of the homogenized medium of the culture has been considered as a parameter of growth in normal studies. But in pollution studies, in presence of pollutants, a consistent data in optical density was never obtained. A decline in dry weight may be due to increased tissue permeability and loss of membrane integrity of plant tissue (Jana and Choudhury, 1982). In addition, dry weight has been considered by good number of workers as a parameter of growth. The changes observed in optical density study exactly do not reflect the real changes induced by the pollutant, but an approximation can be made out from this data. Significant decrease in dry weight in this study indicates the death of algal cells, or depression in growth in exposed algal cells. 
Table 1: Changes in growth parameters and pigment contents in endosulphan, EC- 35 exposed blue green alga (Anabena cylindrical L.) at different exposure and recovery periods

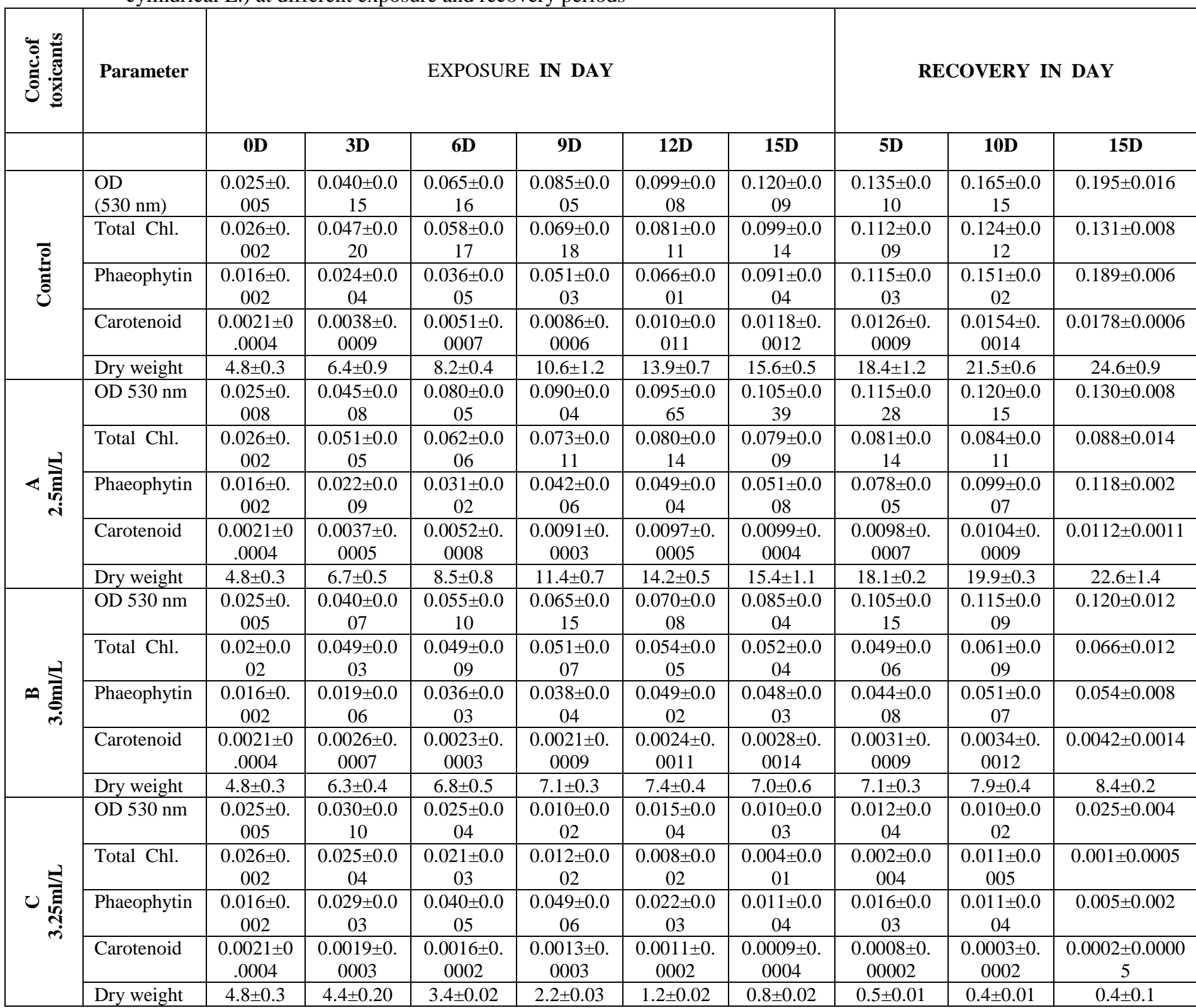

(Data are expressed in Mean \pm S.D of three replicates).

The toxicity of pesticide and mercurial compounds to aquatic flora becomes apparent in a very shorter period. Mercurials have long been recognized as agents which in particular (Webb, 1966). At lower concentrations of mercury based pesticides, an increase in growth rate, pigment content (Rath, 1984; Sahu, 1987) and photosynthetic efficiency was observed (Rath, 1984).

The impact of organic pesticides on algal populations may be considered from various environmental aspects. Pesticides, more specifically herbicides, may exert algaistatic, inhibitory or drastic lethal effects on algae (Bryon and Olafsson, 1978; Werner and Morschel, 1978; Regis at al, 1979a, b). The magnitude of the effects will depend upon the concentration of the pesticide and its selective effect on the various algae populations (Aly et al., 1984) Such selective toxicity will result in material changes in both number and types of algae. Algae tend to accumulate organic pesticides within their cellular matrix.

It can be concluded that pesticides and heavy metals affect drastically the growth, which gets reflected in chlorophyll content (might be inhibiting chlorophyll biosynthesis) and oxygen evolution rate (might be inhibiting photosynthesis) in exposed algae, when compared to control values. It has been shown that cadmium applied as $\mathrm{CdCl}_{2}$ may induce degeneration of mitochondria whose structural integrity is necessary for optimum respiratory activity (Lehninger, 1970). Significant depression in respiration rate of the insecticide exposed blue-green alga was marked, when compared to the control alga, Anabaena cylindrical. Anabaena species is less tolerant when compared to Wesllopsis sps. could tolerate higher concentrations of the pesticide. Anabaena being sensitive to low doses of 
pesticide, disappears from the crop field due to heavy application of killer chemicals. Since in most cases the damage to the organelle may be sufficient to eventually result in cell death.

Many workers have suggested that metals and pesticides are affecting the level of protochlorophyll and carotenoid content but apparently not the degradation of chlorophyll to pheophytin (De Filipps et al., 1981).

Gradual chlorosis at very low concentrations and an instant chlorosis at higher concentrations of pesticide and heavy metals, as well as reduction in the chlorophyll content and biomass were reported (Mhatre and Chaphekar, 1984). Similar results were marked in this piece of investigation on blue-green alga, Anabaena cylindrica. Chlorophyll and carotenoid contents were extrapolated for the measurement of growth of phytoplankton. Chlorophylls are known to be converted to pheophytins as a consequence of exposure to weak acids by replacement of magnesium ion by hydrogen and there by changing the spectral characteristics (Singh and Singh, 1984). Degradation of chlorophyll to pheophytin might be the first step towards the breakdown of chlorophyll. This has been marked in the exposed alga. Initial breakdown of chlorophyll followed by breakdown of pheophytin was marked. With higher increase in concentration of heavy metals and pesticides pheophytin also disingrates. Carotene plays a vital role as a protector of photosynthetic tissued against photosensitized oxidation. The decrease in carotene content in exposed algal cells will lead to decrease in protection from the attack of pesticides to the photosynthetic tissues. The ratio of chlorophyll to carotenoid reflects the environmental conditions. When the nutrients of the medium is exhausted or a pollutant is introduced into the medium the ratio increases due to decrease in chlorophyll content, which reflects the inhibition of chlorophyll biosynthesis.

\section{Acknowledgements}

Authors are thankful to Head, P.G. Department of Botany, Berhampur University, Berhampur, Principal, Khallikote Autonomous College, Berhampur and R.N. College, Dura, Ganjam for providing necessary laboratory and encouragement for research activities.

\section{Reference}

Aly OA, Shehata SA and farag H (1984) Uptake and accumulation of selected herbicides by the freshwater alga Scenedesmus. Arch. Environ. Contam. Toxicol., 13:701705. DOI: $10.1007 / \mathrm{BF} 01055933$

Anderson JR (1978) Hilland IR and Wright SJL (eds) In: Pesticide Microbiology, Academic Press, London, p.313.

Arnon DI (1949) Copper Enzyme isolated chloroplasts, polyphenoloxidase in beta vulgaris, Plant Physiol. 24(1): 1-15. DOI: $10.1104 /$ pp.24.1.1
Arvick JH, Willson DL and Barlington LC (1971) Fixation of elementary Nitrogen by some blue green alga, Weed Sci., 19: 276.

Bryon AM and Olafsson RC (1978) The effect of polychlorobiphenyls (Aroclor 1242) on bicarbonate-C14 uptake by Euglena gracilis. Bull. Environ.Contam. Toxicol. 18: 374-381. DOI: 10.1007/BF01685813

De Filippis LF, Hamp R and Zeigler H (1981) The Effects of Sublethal Concentrations of Zinc, Cadmium and Mercury on Euglena. Growth and Pigments. Z. Pflanzen-physicol. Bd., 101: 37-47. DOI: 10.1016/S0044-328X(81)80059-1

De PK (1939) The role of blue green algae in nitrogen fixation in rice -fields. Proc. R. Soc. B., 127: 121-139. DOI: 10.1098/rspb.1939.0014

Edwards CA (1973) Environmental Pollution by Pesticides. Rothamsted Experimental Station, Harpenden, Hertfordshire, England, Plenum Press, London \& N.Y. DOI: $10.1007 / 978-1-4615-8942-6$

Fogg GE, Stewart WDP, Fay P and Walsby AE (1973) The bluegreen algae. Acad. Press, London and New York, p.459.

Gillberg BO (1971) Effect of some pesticides on Rhizobium and isolation of pesticide-resistant mutants. Arch. Mikrobiol. 75: 203. DOI: $10.1007 / \mathrm{BF} 00408982$

Jana S and Choudhuri MA (1982) Synergic effects of heavy metal pollutants on senescence in submerged aquatic plants. New Phytol. 90: 477. DOI: 10.1111/j.14698137.1982.tb04480.x

Kulasooriya SA, Roger PA, Barraquio WL and Watanabe 1 (1980) Biological Nitrogen fixation by epiphytic micro organism in rice fields. IRRI Res. Pub. Ser. 47: Feb. 1980.

Lehninger AL (1970) Biochemistry,Long term issue of acute idiopathic polyneuritis. Biochemistry. Worth Publ. Inc., New York, p.395.

Mhatre GN and Chaphekhar SB (1984) Response of young plants to mercury. Water, Air, Soil Pollution 21: 1-8. DOI: 10.1007/BF00163606

Rath P (1984) Toxicological effects of pesticides on blue-green algae, Wesllopsis prolifica Janet. Ph.D. thesis, Berhampur University, India.

Regis C, Daniell LM and Jean Guyduberet LB (1979 a) Analysis and characterization of 3-(3,4-Dicholophenyl)-1,1Diethylurea (DCMU) resistant Euglena, Growth, metabolic and structural modification during adaptation to different doses of DCMU. Plant Physiol. 63: 857-865. DOI: $10.1104 /$ pp.63.5.857

Regis C, Daniell LM and Jean Guyduberet LB (1979 b) Analysis and characterization of 3-(3,4-Dicholophenyl)-1,1Diethylurea(DCMU)resistant Euglena. Plant Physiol. 63: 866-872. DOI: $10.1104 / \mathrm{pp} .63 .5 .866$

Rodgers GA, Bergman B, Henriksson E and Udris M (1979) Utilisation of blue-green algae as biofertilisers. Plant and Soil 52: 99. DOI: 10.1007/BF02197736 
Sahu A (1987) Toxicological effects of a pesticide (PMA) on a blue-green alga. Ph. D. thesis, Berhampur University, Orissa.

Singh RN (1961) Role of blue-green algae in nitrogen economy of Indian agriculture. ICAR, New Delhi.

Singh SP and Singh RP (1984) Effect of Sodium metabisulphate on growth and chemical composition of BGA Nostoc cicola. Proc. Ind. Natn. Sci. Acad., B50: 596.

Stewart JG (1977) Relative sensitivity of lead of a naked green flagellate Dunaliella tertiolecta. Water, Air and Soil Pollution 8: 243. DOI: 10.1007/BF00294047
Venkataraman GS (1972) Algal biofertilizers and rice cultivation. Today and Tomarrow's Printers and publications, New Delhi.

Venkataraman GS and Rajyalakshmi B (1972) Relative tolerance of BGA to pesticides. Indian J. Agric. Sci. 2: 119.

Webb JL (1966) Enzymes and metabolic inhibitors. 1st ed., Vol. II, p.729. Academic Press, New York.

Werner W and Morschel E (1978) Preferential elimination of dieldrin by some diatoms compared to Chlamydomonas and Scenedesmus species. Bull. Environ. Contam. Toxicol. 20: 313-319. DOI: 10.1007/BF01683526 